\title{
The Role of Negative Behavior on Children's Academic Performance in Early Childhood Education
}

\author{
Lori A. Smolleck ${ }^{1 *}$ and Christine G. Duffy ${ }^{2}$ \\ ${ }^{1}$ Department of Education, Bucknell University, USA \\ ${ }^{2}$ George Washington University, USA
}

\begin{abstract}
This research examined the results of an observational case study implemented in an early childhood education classroom (Borg \& Gall, 1989). The data analysis identified the most common behavioral issues encountered and how educators addressed and/or attempted to prevent further behavioral issues. "Several factors, both internal (e.g., developmental delays in the areas of social, cognition, and communications skills) and external (e.g., school and home environment), have been found to be related to the development of behavioral concerns in children" (Conroy \& Davis, 2000, p. 164). As such, this research also investigated the possible causes for the behavioral issues. Methods for constructing effective and efficient behavior management are discussed using the data analysis, as well as current research in the field. The overall aim of this research study is to lead educators, administrators, parents, and other individuals working with children toward a better understanding of how and why behavioral issues occur, as well as how these issues can be addressed and prevented.
\end{abstract}

\section{Keywords}

Behavioral concerns, behavioral issues, behavior management, positive behavior support, self-regulation and academic achievement

\section{Introduction}

Citation: Smolleck, L.A., Duffy, C.G. (2017). The Role of Negative Behavior on Children's Academic Performance in Early Childhood Education. Interdisciplinary Education and Psychology, 1(1):8.

Received: July 29, 2017

Accepted: October 31, 2017

Published: November 8, 2017

\section{Copyright: @ 2017 Smolleck et al.} This is an open access article distributed under the terms of the Creative Commons Attribution License, which permits unrestricted use, distribution, and reproduction in any medium, provided the original author and source are credited.

\section{Corresponding author:}

Lori A. Smolleck, Department of Education, Bucknell University, USA

E-mail: Ismollec@bucknell.edu
The society in which we live is "fraught with behavior problems. Crime statistics are rising, interpersonal problems increase, [and] abuse of all types is growing" (Miller \& Cheney, 1996, p. 120). Additionally, "the prevalence of young children at risk for or with behavioral disorders is increasing" (Conroy and Davis, 2000, p. 163).In fact, "researchers suggest that $10-15 \%$ of preschool-aged children demonstrate behavioral problems" (Conroy \& Davis, 2000, p. 163). These behavioral issues negatively impact a child's academic ability, social ability, as well as their emotional development both in and out of school settings.

Beyond the immediate impact behavioral problems have on the specific child exhibiting them, these issues also have a larger impact on the entire learning community as a whole. For example, "student misbehavior adversely affects instruction, the learning environment, and the overall school climate for all learners within the school" (Martens \& Andreen, 2013, p. 313). As a result, investigation of behavioral issues is imperative as it will have strong bearing on the individual child, as well as the entire educational environment in which he or she inhabits.

Hence, the purpose of this research was to explore common behavioral issues found in early childhood educational settings. Specifically, focus was placed on the causes of negative behaviors, as well as strategies and techniques for management and prevention within academic settings. This research examined the results of an observational case study implemented in an early childhood education classroom (Borg \& Gall, 1989). Data analysis identified the most common behavioral issues encountered and how educators attempted to 
address and/or prevent further behavioral issues.

\section{Review of Literature}

"In times when pessimistic views of the future of children are discouraging, schools working with families and the community can create visions of hope and belief in the potential of all children" (Seger \& Koehler, 2011, p. 19). Hence, this research will attempt to shed light on the common behavioral issues exhibited by young children as well as the potential causes. Because, "it is well established that children who exhibit conduct problems (CP) in childhood are at risk of exhibiting serious and persistent antisocial behavior over the course of development" (Waschbusch \& Andrade, 2007, p. 293), the researchers will also offer suggestions for strategies that can be utilized in a variety of situations in order to prevent behavioral issues that may lead to later antisocial behaviors.

For the purpose of this research, we utilized the following definition for behavioral issues/problems we use is as follows: any "behavior emitted by a learner that results in selfinjury, or injury to others, causes damage to the physical environment, interferes with the acquisition of a new skill and/or socially isolates the learner" (Doss \& Reichle, 1991, p. 215). Children may exhibit behavioral issues/problems for a number of reasons. For example, "several factors, both internal (e.g., developmental delays in the areas of social, cognition, and communications skills) and external (e.g., school and home environment), have been found to be related to the development of behavioral concerns in children" (Conroy \& Davis, 2000, p. 164).

Similar to the reasons why behavior problems exist, the causes of behavior problems is also quite variable (Biglan et al., 2012; Cavendish et al., 2014). Specifically, "The direct causes of early behavior problems are unknown; however, we know that a high number of children are exposed to factors that may place them at risk for the development of behavioral concerns" (Conroy \& Davis, 2000, p. 164). Some common causes for behavioral issues typically seen in classrooms include, a desire for any type of attention (i.e. positive or negative, instructional strategies that are not engaging, a lack of structure and/or consistency with procedures and routines. Additionally, another common cause for behavioral problems includes a lack of communicated expectations and follow-through when undesirable behaviors are exhibited. Often times when teachers assign independent work, students struggle to remain on task, which can trigger behavioral issues. Additionally, a lack of awareness of social cues and or social skills can lead to negative behaviors that subsequently can have a negative impact on friendship formation. As such, without a network of friends, children often times can feel isolated which can lead to feelings of anger and frustration. Although a lack of friendships can certainly result in anger and frustration, these negative emotions can have a variety of other origins. For example, peer interactions, school-work that is not developmentally appropriate, as well as, external factors related to a child's life outside of the school environment can all lead to negative behaviors.

Home life can have an enormous impact on student behavior due to the potential imbalance between the expectations of school and home. "Family interactions may determine how members of the family function individually" (Cavendish et al., 2014, p. 52). "Family interactions may determine how members of the family function individually" (Cavendish et al., 2014, p. 52). Family structure and values are complex and as a result, each member of the family can have either a positive or a negative impact on another family member (Cavendish et al., 2014; Biglan et al., 2012; Dishion et al., 2008, p. 15). For example, parent-child relationships that exhibit weak communication and discord are more likely to participate in defiant, antisocial, and other at-risk behaviors at school and in the community (Cavendish et al., 2014;; Biglan et al., 2012; Dishion et al., 2008, p. 15).

Although the family has a major impact on children behaviors, "change in parenting practices indeed translates to improved childhood outcomes" (Dishion et al., 2008, p. 15), even "brief adaptive, and tailored approach to supporting positive behavior support practices can prevent the growth of problem behavior in young children" (Dishion et al, 2008, p. 3). As such, it is important for parents to work in collaboration with schools and or behavior specialists to minimize, decrease and conceivably ameliorate negative behaviors in young children. The more consistent and tailored the approach, the better the results. Furthermore, extending the time by which intervention continues benefits all parties involved and prolongs the positive benefits of the practices. This in and of itself advocates for the importance of 
identifying and addressing negative behavior as early as possible so as to have positive, long lasting results.

Parents and educators spend a great deal of time addressing children's behavioral problems, typically by talking to them and using sanctions and punishments (Dwairy, 2005, p. 144). However, very often, depending upon the particular child, these sanctions and punishments are not motivation for improved behavior. Fortunately, there are more effective, research-based approaches that include family-centered strategies to address problem behaviors that have proven success such as, The Family Check-Up (FCU) intervention, (Bullock \& Forgatch, 2005; Forgatch, Bullock, \& Patterson, 2004; Patterson, 1982; Patterson et al., 1992), the ecological approach to family intervention and treatment (EcoFIT) (Dishion \& Stormshak, 2007) among others. Overall, nurturing environments both at home and at school, provide a critical role for children in relation to their mental, social, emotional and behavioral wellbeing.

\section{Impacton Academic Achievement}

Children who exhibit extreme behavioral issues tend to be easily distracted therefore become off task/have difficulty completing an academic assignment, which then leads to frustration. The reason children have difficulty staying on task in the classroom is due to a lack of self-regulation. "Strong behavioral self-regulation has been linked to better academic achievement for children in grade school" (Montroy, 2015, p. 299). Self-Regulation is "a broad concept referring to the process whereby an individual deliberately utilizes his or her skills and attributes to create an overt response to the ongoing demands of the environment in a manner that is contextually appropriate" (Montroy, 2015, p. 299). As a result, this feeling of frustration we mention is present for these children due to their inability to self-regulate.

The feeling of frustration can be demonstrated through a variety of extreme behaviors which include, defiance to complete tasks, anger when redirected, difficulty getting along with classmates, aggressive behavior towards classmates and/or teacher, blurting out random thoughts at inappropriate times, unpredictability, and unresponsiveness. Regardless of the behavior being presented, frustration is typically the origin. Hence, this feeling ultimately has a major impact on their academic achievement in the classroom.

Additionally, self-esteem also plays a key role within the area of academic achievement. For example, a child that has difficulty focusing or completing a task, feels as if he/she are incapable of meeting certain academic expectations. Hence, they simply avoid situations where they have low self-efficacy (Bandura, 1977). In avoiding these situations, self-esteem decreases, as well as their true ability to do the tasks. As a result, the students do not have as much exposure to these academic experiences and do not have the opportunity to practice and improve their academic concepts and skills, which can result in lower academic success. It is a vicious cycle that impacts both academic achievement and students' overall selfesteem.

Extensive research has been conducted that established a causal relationship between behavioral issues and academic achievement. There are two aspects of children's functioning, "social skills and problem behaviors, that mediate the relationship between preschool self-regulation and literacy and math achievement" (Bowles et al., 2015, p. 298). Furthermore, it has been proven "that a child's social skills and problem behaviors are a part of the mechanism through which behavioral self-regulation affects growth in literacy" (Bowles et al., 2015, p. 298). Overall, it is evident that these behaviors can influence a child's academic achievement, as well as his/her social, and/or emotional states.

\section{Method}

\section{Purpose}

This research utilized an observational case study within an early childhood education classroom to investigate the most common behavioral issues exhibited by young children (Borg \& Gall, 1989).Additionally, the researchers investigated the ways in which teacher(s) addressed and/or attempted to prevent further behavioral issues.

\section{Participants}

This research was conducted in a second-grade classroom, which included 18 students in a public school in central Pennsylvania. The observational case study took place over the 
course of four months in the spring of 2015.Over this period of time, the researchers conducted approximately 15 sessions in the classroom to closely monitor specific misbehaviors being exhibited. While observing, the researches came to the conclusion that only two of the students in this classroom were exhibiting extreme misbehavior, which needed both attention and immediate assistance.

The researchers were able to work closely with students during this time and as a result implemented various behavioral interventions strategies with specific students in the classroom to determine effectiveness.

During the observations, the researchers examined the classroom for the most common behavioral issues outlined above in the literature review. As such, based on the behaviors exhibited by the children, the researchers implemented the prevention strategies that seemed most appropriate for the specific behaviors displayed.

The behavioral intervention strategies utilized were: Self-Regulation, the CLEAR model, Positive Behavior Support, Functional Behavior Assessment, and Problem-Solving Conversation. These methods were chosen due to the type of consistent behavior exhibited during observations that proved to be disruptive to the classroom learning environment. Each of these intervention strategies are elaborated upon and fully explained in the 'Implementation Strategies' section of this manuscript.

Through the observation process, the researchers were able to investigate the possible causes of these extreme behaviors and analyze the patterns in which they occurred in the classroom setting. The researchers were able to track these consistent misbehavior patterns as well as trigger patterns through the act of thorough note taking which stemmed from close observation of specific students. This tracking/coding system was used consistently throughout the observation process where the researcher would mark and specify the time and place a student exhibited any type of disruptive, defiant, unresponsive, and uncooperative behavior. After multiple observation sessions, the researchers analyzed their data and found certain patterns in particular student's classroom behavior. Once it was decided that a student was demonstrating a form of misbehavior, they were categorized as a student who needed assistance with the implementation of a certain behavior management strategy. The data collection and analysis process aided the researchers to choose the most appropriate type of management strategy that was ultimately the most effective on the student's overall demeanor in the classroom.

As a result, this research was successful in identifying the most common behavioral issues, implementing strategies and uncovering the causes of these extreme behaviors so as to attempt to prevent such disruptive behaviors in future situations.

\section{Results}

The most common behavioral issues encountered during this observational case study were: the inability to complete tasks, the expression of defiant behavior when presented with academic tasks to complete, anger when a child was redirected to continue working on academic tasks, difficulty creating and maintaining relationships with peers, the presentation of aggression towards peers and at times the teachers, blurting out random thoughts at inappropriate times, unpredictable emotional outbursts, and unresponsiveness to authoritative direction.

Furthermore, through the process of observation, the researchers were able to identify the causes and/or triggers that preceded the negative behavior. For example, the amount of attention provided to a particular student at times determined behavior. Specifically, more attention typically lead to cooperation and less disruptive behavior, which ultimately would have a positive impact on academic achievement. However, students also at times exhibited attention seeking behavior from adults in both positive and negative manners. Typically, students did not seem to concern themselves with what type of attention they received from the adults in the classroom, as long as they were receiving attention, they appeared to be satisfied.

In response to assigned academic tasks, students typically needed a strong sense of structure provided in order to have a positive experience without any emotional outbursts or negative behaviors. Furthermore, if a student was instructed to participate in independent work, the lack of structure would result in an exhibition of negative behaviors in order to seek 
attention, from either their peers and or adults in the classroom. Therefore, this attention seeking behavior negatively affected their academic achievement.

Relationships with peers is an essential part of a child's development. In response to negative attention given by peers, a student may have the inability to form relationships with their classmates, which is why they display negative behaviors. Due to this inability to form friendships, this may be caused by an unawareness of social cues. Because of the lack of social cues and inability to form strong relationships, this could lead to a sense of anger which could then act as a catalyst for multiple exhibitions of negative outbursts which all aim to seek any sort of attention.

Overall, in the end, it is important to recognize that at times it is quite possible, depending on the age of the child, that children are not developmentally equipped to negotiate these skills. Due to this inability to navigate emotional situations, it is beyond a child's own emotional and social abilities given their particular stage of development (Erikson, 1993).

Home lives were another cause of disruptive behavior in the classroom. Although this factor is strongly supported and has been investigated by an array of research studies (Doss \& Reichle, 1991; Conroy \& Davis, 2000; Dwairy, 2005; Martens \& Andreen, 2013), it is a difficult factor to address. For example, some of the children in this study had very difficult home lives and as a result, understandably so, had negative attitudes, which impacted their social, academic, and emotional states. However, there is a limit on what a teacher can do to address issues at home, particularly when parental involvement is lacking or non-existent. Although the teacher(s) in this observational case study reached out to the families of disruptive students in an attempt to work collaboratively for the betterment of the child, at times the parents were uninterested, in denial, or truly could not participate due to a lack of resources (i.e. car, work schedule, family responsibilities, etc.).

\section{Implementation Strategies}

"The Individuals with Disabilities Education Act (IDEA), has required schools to provide positive behavior supports for students whose behavior impedes learning" (Seger \& Koehler, 2011 , p. 17). As such, the researchers investigated a number of behavior supports that could be implemented in a variety of classroom settings with a variety of students. For the purposes of this study, the strategies that proved to be the most successful were, Self-Regulation, Positive Behavior Supports, and Problem-Solving Conversations.

\section{Self-Regulation}

Self-Regulation is "a broad concept referring to the process whereby an individual deliberately utilizes his or her skills and attributes to create an overt response to the ongoing demands of the environment in a manner that is contextually appropriate" (Montroy, 2015, p. 299). Self-regulation is a skill that is formed at a young age and is proven to improve academic achievement. It is also found that, "... a child's social skills and problem behaviors are part of the mechanism through which behavioral self-regulation affects growth in literacy. Selfregulation may be important not just because of the way that it relates directly to academic achievement but also because of the ways in which it promotes or inhibits children's interactions with others" (Montroy, 2015, p. 299).

When using self-regulation, the researchers modeled desired behavior and scaffolded experiences through dialogue with the children. Eventually less scaffolding was used and students began to implement the expected behavior in the classroom. A supportive framework was continuously utilized throughout the process so that students felt successful, particularly when external factors of the environment could interrupt their behavioral progress. It was important for the researches to continually check in with the students to ensure progress. SelfRegulation takes time and requires the teacher/adult in the situation to break larger tasks into smaller more manageable increments so as to build the self-confidence of the child.

Overall, self-regulation was successful in that it helped students to realize that they could in fact control their own emotion and/or behavior. It was especially useful for students to have dialogue with the researchers so that feedback and support could be provided. Scaffolding and task management were also particularly useful because this allowed the children to see the 'goal' in smaller increments instead of a large, overwhelming task to be completed.

\section{Positive Behavior Support Strategy}

Another behavioral prevention and management strategy that the researchers used during 
the observational case study was The Positive Behavior Support Strategy (PBS). Positive Behavior Supports is the "application of positive behavioral interventions and systems to achieve socially important behavior change" (Sugai et al., 1999, p. 6). "Positive Behavior Supports are widely used to deal with disruptive behavior in schools" (Seger \& Koehler, 2011, p. 17).Additionally, PBS provides an individualized behavior modification plan which outlines specific tasks and behaviors to be achieved. When these desired behaviors are displayed, positive feedback from a teacher and/or adult is provided. The foundation on which PBS is built, is on positive reinforcement of desirable behavior (Seger \& Koehler, 2011; Carr et al., 2002; Sugai \& Horner, 2006, Reinke et al., 2013).

When using the Positive Behavior Support Strategy, the researchers provided specific behavior modification plans for particular students who exemplified extreme behaviors in the classroom. For example, there were two students who demonstrated severe anger issues and lack of self-control in the classroom setting. These behaviors were considered to be more extreme than typical child misbehavior. Therefore, these students were exposed to the Positive Behavior Support Strategy when working on improving their overall behavior in the classroom. Since these students had anger issues, their plan consisted on "cool-down" strategies and a variety of ways in which the students could learn to practice self-control.

The main goal of this behavior management strategy was to highlight the preferred behaviors and maintain consistency throughout the implementation of this strategy. Because this strategy relies so heavily upon the use of positive feedback, it is essential to implement this strategy with students who respond to this type of communication. (Seger \& Koehler, 2011; Carr et al., 2002; Sugai \& Horner, 2006, Reinke et al., 2013).

Overall, PBS was a successful behavior strategy, particularly with students who responded well to positive reinforcement. The positive reinforcement from adults was motivation for the students to adjust their behavior in order to 'please' those around them. Thus, PBS served as a, "catalyst for the child's behavioral improvement" (Sugai, et.al., 1999, p. 9).

\section{Problem Solving Conversation}

"Problem Solving Conversation (PSC) with children comprises a structured interview that parents, educators, counselors, and therapists can implement. It consists of four stages: listening to the child, probing reevaluation, exploring alternatives and setting a new plan, and follow up. It facilitates the development of the child's ego, personal growth, and sense of responsibility and is an aid to dealing with children's daily behavioral problems as well as more global issues" (Dwairy, 2005, p. 144).

When using this strategy, the researchers talked through problems with the children and allowed the children to come to the realization of the wrongdoing in their actions with the help from an authoritative figure. This strategy involved a very communicative form for solving problems where the students were involved in finding alternatives, and their opinions were valued. Hence, the researchers observed that the students felt more validated in their own ideas and more responsible for their change in behavior as well as their subsequent successes. According to our observations, one of the students who portrayed negative behavior in the classroom responded very well to problem solving conversation because it allowed them to talk through their feelings and thoughts and also be a part of the solution to the problem. This particular student was arguing with one of his peers and was having trouble sharing with him. However, before the problem became too immense, the researcher decided to step in and implement one of the management strategies. The researcher listened to both children and their side of the problem, guided the conversation by helping each of them reevaluate their side, discuss alternative solutions, and creating a plan for next time sharing becomes a problem. The researcher saw this behavior prevention and management strategy in action and saw the positive short and long-term effects on the students and their learning environment.

From our observations, it was evident that this strategy can improve a child's self-regulating skills because it clearly marks which behaviors are acceptable in the classroom as well as the potential alternatives for behaviors that can lead to resolving behavioral issues and/or concerns.

Overall, Problem Solving Conversation was a successful strategy because the four stages involved in Problem Solving Conversation provided a simple yet realistic structure for which the researchers and child could effectively utilize in order to improve problematic behavior. 
The framework of the four stages provide a sort of 'safety net' for times when difficulty arose. It was uncomplicated for the researcher and children to simply start again and reevaluate progress within the framework of the four stages. Again, the discussion based nature of this strategy allowed for open communication between the researchers and children to optimize success, as well as allow for opportunities for conversation regarding difficulties, complications, worries, etc.. Furthermore, the conversational tone of this strategy was also useful for monitoring progress.

Although the three particular strategies mentioned above were utilized for this particular research study, there are a number of other methods that could also be implemented and be beneficial for behavioral issues. For example, methods such as the CLEAR Method and Functional Behavior Analysis have noted effectiveness with dealing with behavioral issues and/or concerns.

\section{The CLEAR Method}

The CLEAR Method is a behavioral prevention strategy that concentrates on positive behavioral attributes and possible solutions to any problems that arise. Specifically, "the CLEAR Team Problem Solving model shifts the focus from deficits to strengths and solutions. The goal is to identify how a child's private logic and interpersonal conflicts serve to maintain maladaptive behavior" (Seger \& Koehler, 2011, p. 16). In order to utilize this method, the behavior team must consist of a trained facilitator. This facilitator would have specific education and instruction with the Clear Method. The Clear Method utilizes a team approach, of which the student is the most important member of the team (Seger \& Koehler, 2011). Other members of the team may consist of supportive teachers, administrators and at least one parent or guardian (Seger \& Koehler, 2011). The goal for creating the team in such a way is to allow the student to view the team as their advocate. "This connection builds the trust that paves a path for change. Getting adults who support the student, especially in the eyes of the youth, is critical" (Seger \& Koehler, 2011, p. 18).

In summary, the Clear Method, developed by Brendtro and du Toit (2005), consists of five specific steps that include a great deal of cooperative brainstorming, by which "the brain processes behavioral events"

- $\quad$ CHALLENGES produce stress triggering

- LOGIC which combines with

- $\quad$ EMOTIONS which drive

- $\quad$ ACTIONS that lead to

- $\quad$ RESULTS or consequences (Seger \& Koehler, 2011, p. 17).

Due to the structure utilized by the Clear Method, team members learn how to uncover students' needs and create a positive, supportive, and effective plan to overcome any behavioral obstacles students may face. "This optimistic mindset is critical to help students make true behavior change" (Seger \& Koehler, 2011, p. 17).

As previously mentioned, the three particular strategies that were most successful for this particular research study were Self-Regulation, Positive Behavior Support Strategy, and Problem-Solving Conversation. As a result, the researchers did not employ the CLEAR Method. Nonetheless, this method certainly could be implemented and be beneficial for children exhibiting behavioral issues in classroom settings, as it has proven reliability with such populations (Brendtro et al., 2012).

\section{Functional Behavioral Assessment}

Another notable behavior management strategy that can be implemented into the classroom is Functional Behavioral Assessment (FBA). Although this FBA was one of our potential behavior management strategies, we ultimately did not utilize this strategy because we found that it did not particularly fit with the needs of the participants being observed.

Functional Behavioral Assessment "is the process of determining relations between specific variables in the environment and problem behavior (Davis, 1998)" (as cited in Conroy and Davis, 2000, p. 163). "The disciplinary provisions outlined in IDEA (1997) mandate the use of functional behavioral assessment (FBA) for students who have disabilities (including students who are suspected of having a disability) who demonstrate behavioral concerns that place them at risk for suspension and expulsion" (Conroy and Davis 2000, p. 164). 
"This FBA process includes (a) defining the challenging behavior, (b) determining the environmental events and factors that contribute to the challenging behavior, (c) using direct observation to identify the antecedents and consequences that occur before and after the challenging behavior, (d) developing hypotheses regarding the function of the behavior and the contextual factors that contribute to the challenging behavior, (e) validating these hypotheses, and (f) developing an efficient and effective intervention that matches the function of the behavior (Dunlap \& Kern, 1993)" (Conroy \& Davis, 2000, p. 164).

Overall, the benefit of using this strategy is similar to many of the other strategies, to either eliminate or decrease behavioral challenges. Functional behavioral Analysis includes attention to the environment that may be a factor for the problem behaviors and considers how to reduce these environmental factors. In turn, the expectation is that with the reduction of 'triggers' from the environment, students can improve their behavior in the classroom and as a result allow for more instructional time for the teacher, as well as learning for the student(s).

\section{Conclusions}

The main purpose of this conducted research was to examine common behavioral issues found in early childhood educational settings. "A challenging behavior is any "behavior emitted by a learner that results in self-injury to others, causes damage to the physical environment, interferes with the acquisition of a new skill and/or socially isolates the learner" (Doss \& Reichle, 1991, p. 215)

This research examined the results of an observational case study implemented in an early childhood education classroom (Borg \& Gall, 1989). Overall data analysis identified the most common behavioral issues encountered and how educators attempted to address and/or prevent further behavioral issues. Each of these behavioral issues as well as their prevention strategies were outlined in detail above.

"Several factors, both internal (e.g., developmental delays in the areas of social, cognition, and communications skills) and external (e.g., school and home environment), have been found to be related to the development of behavioral concerns in children" (Conroy \& Davis, 2000 , p. 164). "For strategies to be effective, these must be perceived by both students and adults as meeting their needs. But adults who do not understand the challenges or stress through a youth's eyes can easily miss the mark on what truly drives the behavior and what supports are needed. When adults view these youth through pessimistic lenses, interventions lack the spirit and conviction that true change requires" (Seger \& Koehler, 2011, p. 17).

\section{Discussion/Implications}

\section{Research}

As with any research, this study revealed a great deal about behavioral issues, however it also opened up new avenues of questioning. Further research regarding behavioral issues in the area of assessment of the particular behavior and finding the best strategies is most definitely warranted. In addition, given that parents tend to know their children in ways that are different than the school/educational system in which they are enrolled, parental involvement is another factor to consider including in further research. "Exploratory factor analyses examined whether a core set of component constructs assessing qualities of children's relationships, caregiver involvement and monitoring, and experiences in school and aftercare contexts that have been linked to children's behavior problems would emerge" (Ingoldsby et al., 2012, p 893).

Gender differences are another area associated with both behavioral issues and particular strategies and interventions that would be worthy of consideration. For example, investigating the "possibility that two aspects of children's social functioning, social skills and problem behaviors, mediate the relationship between preschool self-regulation and literacy and math achievement" (Bowles, et al., 2015, p. 298).

\section{Policy}

Additionally, utilizing a faster process in relation to the identification of students with behavioral issues and concerns would be most useful to teachers, parents, and school personnel. This faster process would assist in addressing the behavioral issues in a more educated and research based manner. 
Professional development is critical from state and administrative end of the school systems. All teachers need to be educated in identifying, addressing, and regulating severe behavior issues in the classroom. It is important to understand that NOT all teachers have this knowledge as a result of their college/university degrees. Specifically, many universities and colleges do not offer dual certification in both Special Education and Early Childhood education. Hence, it would be advantageous for schools, school districts, and school systems to offer training in these particular areas so that all teachers at least have a strong understanding of how to determine, attend to, and adjust to the problem and/or at risk behavioral issues. Having teachers understand how to implement strategies such as those outlined in this paper will not only assist their methodology of teaching, but it would also foster better relationships between and among students within the classroom. "For example, positive relationships with teachers and peers in school have been shown to build children's self-esteem and social competence and to confer protection for children at risk for behavioral or learning issues" (Ingoldsby et al., 2012, p. 894).

\section{Practice}

Similar to the need for professional development mentioned above, educators cannot do better unless they know better. It is astonishing how many teachers have not even heard of FBA, the CLEAR method, or Positive Behavior Support Strategy, to name only a few, for example. If school systems could provide more professional development in the areas of identifying, addressing, and managing problem or at risk behavioral issues, it, in a way comes back to the common quote, "An individual can only do better if they know better." If we expect our teachers to manage classrooms better and more effectively, then professional development opportunities to do so must be provided to assist their professional growth and understanding.

Professional development that assists teachers in implementing interventions that best fit the child as well as the behaviors being exhibited is of the utmost importance, particularly in relation to academic success. Specifically, "strong behavioral self-regulation has been linked to better academic achievement for children in grade school" (Bowles et al., 2015, p. 299).

Adapting instruction most effectively to the needs of the child not only provides assistance to the teacher in reaching academic goals, it also has a significant impact on social development as well. As stated earlier, students with behavior complications struggle to form and cultivate and maintain peer relationships. Hence, "... a child's social skills and problem behaviors are part of the mechanism through which behavioral self-regulation affects growth in literacy. Selfregulation may be important not just because of the way that it relates directly to academic achievement but also because of the ways in which it promotes or inhibits children's interactions with others" (Bowles et al., 2015, p. 298).

\section{Limitations}

Due to the fact that this research was conducted in one second grade classroom with 18 students in central Pennsylvania, one could argue that the results are not generalizable. However, it is important to note that the most common behavioral issues that were uncovered are present in the majority of classrooms (Dunlap \& Kern, 1993; Conroy \& Davis, 2000; Martens \& Andreen, 2013; Seger \& Koehler, 2011). As such, the strategies chosen to ameliorate these behavioral issues can be utilized in a multitude of settings and classrooms. What is important to recognize is that the strategies that are chosen and implemented should not be done without thoughtful consideration of the behavior and the specific causes. For example, a teacher must first "Assess the frequency and quality of key characteristics and experiences across children's diverse settings; in particular, to capture these characteristics from a dyadic perspective rather than a static count of individual behaviors" (Ingoldsby et al., 2012, p. 900). Hence, the strategies chosen should represent the behaviors being displayed.

Additionally, because this research study took place over the span of 13 weeks, long term and subtle effects have not been explored fully. As a result, more research that follows participants for longer periods of time would be advantageous. Furthermore, because this was an observational case study, the researchers had no real control over the makeup of the control group. As a result, we were not able to randomize the allocation of subjects. "This can create and can also mask the cause and effect relationships or. Alternatively, suggest correlations. Randomization is assumed to even out external causal effects, but this is impossible in an observational case study" (Shuttleworth, https://explorable.com/ 
observational-study). Lastly, with observational case study research, "there is no independent variable"...as a result "it is dangerous to assume cause and effect relationships with unfounded results" (https://explorable.com/observational-study).

Although there are certainly limitations to observational case study research, it is very important within the field of social sciences. "An observational study allows a useful insight into a phenomenon," which may not have otherwise been achieved "an observational study allows a useful insight into a phenomenon" (https://explorable.com/observational-study).

\section{Funding}

No funding was provided for this research.

\section{Author Biography}

Lori A. Smolleck is an Associate Professor of Education and Chair of the Education Department at Bucknell University. She has been teaching for $21+$ years and is a certified classroom teacher with a concentration in special education. Additionally, she has had extensive training in Applied Behavior Analysis and has worked as a ABA Technician. Specifically she was employed by a growing company serving the Maryland, Northern Virginia, and Pennsylvania areas. She has offered in-home ABA therapy and support to clients with issues related to Autism, Fragile $X$, behavioral problems, communication disorders, and those in need of self-help skills and or social skills.

Christine G. Duffy has had extensive training in Early Childhood Education through a thorough training program provided by Bucknell University. This training program included a variety of informative classes as well as classroom training about child development, behavior, and much more. This training program required the researcher to student teach in a classroom for a four-month period to better understand how the classroom environment worked on a daily basis. This allowed the researcher to have an inside look of the classroom setting and how and when certain behaviors occur. 


\section{References}

Bandura, A. (1977). Social learning theory. New Jersey, NJ: Prentice Hall.

Biglan, A., Flay, B., Embry, D., \& Sandler, I. (2012). The critical role of nurturing environments for promoting human wellbeing. American Psychologist, 67(4), 257-271.

Borg, W.R., \& Gall, M.D. (1989). Educational Research: An introduction - fifth edition. New York, NY: Longman.

Brendtro, L. \& du Toit, L. (2005). Response ability pathways: Restoring bonds of respect. Cape Town, SA: Pretext.

Brendtro, L. K., Mitchell, M. L., Freado, M., \& du Toit, L. (2012). The developments audit: From deficits to strengths. Reclaiming Children and Youth; Bloomington, 21(1), 7-13.

Carr, E., Dunlap, G., Horner, R., Koegel, R., Turnbull, A., Sailor, W., ..., Fox, L. (2002). Positive behavior support: Evolution of an applied science. Journal of Positive Behavior Interventions, 4(1), 4-16.

Cavendish, W., Montague, M., Enders, C., \& Dietz, S. (2014). Mothers' and adolescents perceptions of family environment and adolescent social emotional functioning. Journal of Child Family Studies, 23, $52-66$.

Conroy, M. A. \& Davis, C. A. (2000). Early elementary-aged children with challenging behaviors: Legal and educational issues related to IDEA and assessment. Preventing School Failure, 44(4), 163-168.

Dishion, T., Connell, A., Weaver, C., Shaw, D., Gardner, F., \& Wilson, M. (2008). The family check-up with high-risk indigent families: Preventing problem behavior by increasing parents' positive behavior support in early childhood. Child Development, 79(5), 1395-1414.

Doss, L. S. \&Reichle, J. (1991). Replacing excess behavior with an initial communicative repertoire. In J. Reichle, J. York, \& J. Sigafoos (Eds.), Implementing augmentative and alternative communication: Strategies for learners with severe disabilities. Baltimore, MD: Brooks Publishing Co.

Dunlap, G., \& Kern, L. (1993). Assessment and intervention for children within the instructional curriculum. In J. Reichle\& D.P. Wacker (Eds.), Communicative approaches to the management of challenging behaviors (pp. 177-203). Baltimore, MD: Paul H. Brookes Publishing Co.

Dwairy, M. (2005). Using problem-solving conversation with children. Intervention in School and Clinic, 40(3), 144-150.

Erikson, E. H. (1993). Childhood and Society. New York, NY: W. W. Norton \& Company Inc.

Ingoldsby, E.M., Shelleby, E.C., Lane, T., Shaw, D.S., Dishion, T.J., \& Wilson, M.N. (2012). The aftercare and school observation system (ASOS): Reliability and component structure. Journal of Child and Family Studies, 22, 893-902.

Martens, K. \& Andreen, K. (2013). School counselors' involvement with a school-wide positive behavior support intervention: Addressing student behavior issues in a proactive and positive manner. Professional School Counseling, 16(5), 313-322.

Miller, E. R. \& Cheney, C. D. (1996). Teaching children behavior science for problem prevention purposes. Education, 17(1), 120-127.

Montroy, J.J., Bowles, R.P., Skibbe, L.E., \& Foster, T.D. (2015). Social skills and problem behaviors as mediators of the relationship between behavioral self-regulation and academic achievement. Early Childhood Research Quarterly, 29, 298-309.

Reinke, W., Herman, K., \& Stormont, M. (2013). Classroom-level positive behavior supports in schools implementing SW-PBIS: Identifying areas for enhancement. Journal of Positive Behavior Interventions, 15(1), 39-50.

Seger, V. \& Koehler, N. (2011).The CLEAR problem solving model: Discovering strengths and solutions. Reclaiming Children and Youth, 20(1), 16-20.

Shuttleworth, M. (2009). In the fields of social science psychology and medicine, amongst others, observational study is an essential tool. Retrieved from https://explorable.com/observational-study.

Sugai, G., Horner, R. H., Dunlap, G., Hieneman, M., Lewis, T. J., Nelson, C. M,... , Ruef, M. (1999). Applying positive behavioral support and functional behavior assessment in schools. Eugene, OR: University of Oregon, OSEP Center on Positive Behavioral Interventions and Supports.

Sugai, G., \& Horner, R. (2006). A promising approach for expanding and sustaining school-wide positive behavior support. School Psychology Review, 35(2), 245-259. 
Waschbusch\& Andrade, (2007). Social problem solving, conduct problems, and callous-unemotional traits in children. Child Psychiatry Human Development, 37, 293-305. 